Original Contribution

\title{
EFFECTS OF THE ETHANOLIC EXTRACT OF ROSA CANINA ON SOME SERUM BIOCHEMICAL FACTORS IN DIABETIC ADULT MALE RATS
}

\author{
S. M. Banan Khojasteh ${ }^{1}$, El. Basirat ${ }^{1}$, F. Sheikhzadeh ${ }^{1}$, S. A. Ozy ${ }^{1}$, G. Dehghan ${ }^{1}$, \\ H. Hatami ${ }^{1}$, N. Farsad ${ }^{2}$ \\ ${ }^{1}$ Department of Animal Biology, Faculty of Natural Sciences, University of Tabriz, Tabriz, Iran \\ ${ }^{2}$ Department of Plant Biology, Faculty of Natural Sciences, University of Tabriz, Tabriz, Iran
}

\begin{abstract}
Medicinal plants play a main role in the management of diabetes mellitus especially in expanding countries where resources are few. Rosa canina L. is a medicinal plant largely used in common folk medicine. The aim of present research is studying effects of Rosa canina extract on amounts of serum biochemical factors in diabetic male rats. In this experiment, 32 male Wistar rats were obtained and randomly divided into four groups $(\mathrm{n}=8)$. These groups received normal saline $(10 \mathrm{mg} / \mathrm{kg}), \mathrm{RC}$ fruit extract $(250 \mathrm{mg} / \mathrm{kg})$ and $\mathrm{RC}$ fruit extract $(500 \mathrm{mg} / \mathrm{kg})$ as oral gavages every day for a period of four weeks, respectively. glucose, cholesterol and triglyceride levels in the serum were determined at the end of the period. The results showed that glucose, cholesterol and triglyceride concentrations were significantly increased in the diabetic group. The levels of glucose, cholesterol and triglyceride significantly decreased in the treatment groups in comparison with the diabetic control group $(\mathrm{p}<0.05)$. The changes of glucose,triglyceride in treatment groups showed no significant differences. In contrast the cholesterol differences in groups receiving extract was significant in comparison with the normal saline group.
\end{abstract}

Key words: Diabetes mellitus, Rosa canina, rat, hypoglycemia

\section{INTRODUCTION}

Diabetes mellitus is an important metabolic disorder that is distinguished by hyperglycemia resulting from defects in insulin secretion, action or both. It has formerly been established that chronic hyperglycemia of diabetes is relevant with long term damage, dysfunction and finally the failure of organs, especially the eyes, kidneys, nerves, heart and blood vessels. The outbreak of occur diabetes in nearly $6 \%$ of the population and the diabetes type 2 constitutes 90 to $95 \%$ of it. The complications are the principal reason of morbidities and mortalities in diabetes.

In the presence of insulin, glucose is used but lipids and proteins are reserved in the body. In diabetes mellitus insulin deficit leads to defeat of glucose utilization consequently in breakdown of lipids and proteins.

*Correspondence to: Elaheh Basirat, Department of Animal Biology, Faculty of Natural Sciences,

University of Tabriz, Tabriz, Iran,

elahebasirat@yahoo.com
While insulin and oral antihyperglycemic drugs such as biguanides, sulfonylurease, thiazolidinediones and alpha glucosidase inhibitors are the basis of the diabetes treatments they have important adverse effects and cannot always maintain euglycemia and prevent diabetes complications significantly. Therefore there is a continuing need for alternative antidiabetic therapy with better risk-advantage rations and further patient admissibility. It is important to investigate both the antioxidant potential and the hypoglycemic activity of antidiabetic drugs. Therefore, antidiabetic researches are still continuous increasingly. Plants have always been sources of drugs and many of the existing drugs have originated from plants directly or indirectly. Ethnobotanical studies have reported more than 1200 plant species with potential antidiabetic effects.

The genus Rosa with over 100 species is one of the most widespread members of the Rosaceae family. This genus is extensively scattered in Europe, Asia, the Middle East and North 
America. It is frequently used for the prevention and treatment of the common cold, gastrointestinal disorders, diabetes, kidney disorders, and other infections. The role of this plant peaked during the World War II when the syrup of rose hips, exceedingly rich in vitamin $\mathrm{C}$, was introduced in the diet to overcome the deficiency of fresh citrus fruits and then to prevent the scurvy. Because of its popularity as a medical remedy, Rosa canina L. has become a popular research subject for researchers, as well. Researchers have shown that the utilization of Rosa canina L. as a remedy in traditional folk medicine comes from its high content of phenolic compounds and minerals. In particular Rosa canina L. is a great source of ascorbic acids, tocopherols, bioflavonoids, tannins, pectin, minerals, amino acids, flavonoids, unsaturated and polysaturated fatty acids, phospholipids, minerals, galactolipids, and carotenoids.

Streptozotocin (STZ) is a valuable factor for induction of experimental diabetes mellitus. In this model, STZ can stimulate free radical production, which may be one of the most essential causes of $\beta$-cell damage and its diabetogenic effect. Thus, STZ-induced diabetic model is preferred to act diabetes and oxidative stress described above.

$\mathrm{RC}$ is a Mediterranean medicinal plant which widely used in Iran northwest. In the present work, we evaluated the possible potential of RC as an antidiabetic in rats and its effects on some biochemical parameters.

\section{MATERIAL AND METHODS}

Plant material and extraction: Samples of RC growing wild in northwest Iran were collected in October and its identity was authenticated by a botanist. The material was dried in the dark at room temperature before extraction. Dried fruits (about $1 \mathrm{~kg}$ ) were submitted to extraction with $300 \mathrm{ml}$ ethanol (Merck) and distilled water mixture $(1: 1)$ in a Soxhlet apparatus for $10 \mathrm{~h}$. After extraction, the solvent was filtered and then evaporated by rotary evaporator in $45^{\circ} \mathrm{C}$ and extract yield was recorded and then stored at $4^{\circ} \mathrm{C}$ in sealed glass vials until tested and analyzed.

Experimental animals: Male Wistar rats weighting 180- 220g were obtained (University of Medical Sciences, Tabriz, Iran) a week before the start of the experimental treatments. Throughout the experimental period, the animals
KHOJASTEH S. M. B., et al.

were fed a pelleted commercial chow diet and had free access to water, and were kept in separate standard cages in a well-ventilated room maintained at $21 \pm 2^{\circ} \mathrm{C}$ with a $12: 12 \mathrm{~h}$ light: dark cycle. In all the experiments, the animals were treated on the basis of international law and care of laboratory animals.

Treatment protocol: After a week of acclimatization, the animals were randomly divided into four groups of 8 rats in each group. Group I received normal saline $(10 \mathrm{mg} / \mathrm{kg})$ (intact control). Group II were diabetic rats. Group III, used as the first treated group, was given $250 \mathrm{mg} / \mathrm{kg}$ of extract, and group IV, used as the second treated group, and was given $500 \mathrm{mg} / \mathrm{kg}$ of RC extract for 28 days (were administered orally, every $24 \mathrm{~h}$ for a period of 28 days). The experimental rats were carefully monitored every day; no sign of toxicity was noticed on the behaviors and general health of the rats when exposed to the plant extract. At the end of the experimental period, the fasted rats were anesthetized by intraperitoneal injection of $100 \mathrm{mg} / \mathrm{kg}$ ketamine and $5 \mathrm{mg} / \mathrm{kg}$ xylazine and sacrificed. the blood samples were obtained From the retro orbital sinus and was centrifuged at $3000 \mathrm{rpm}$ for $10 \mathrm{~min}$ for serum sepration. The body weight of all rats was measured.

Induction of diabetes: Diabetes was induced by the intraperitoneal (i.p.) injection of streptozotocin at a dose of $60 \mathrm{mg} / \mathrm{kg}$ b.w. dissolved in citrate buffer (1 M, pH 4.5) (1 $\mathrm{ml} / \mathrm{kg}$ ). Forty-eight $\mathrm{h}$ after STZ injection, blood samples were obtained from the tail vein and blood glucose concentrations were measured with a Surestep glucometer. The blood glucose levels higher than $250 \mathrm{mg} / \mathrm{dl}$ were considered to be diabetic, after a week that animals showed diabetic behavior such as polyuria and Polydipsia.

Statistical analyses: Data were examined using a commercially available statistical package (SPSS version 19 for Windows), and comparisons were made using the one way ANOVA and regression.

\section{RESULTS}

Effects of Rosa canina L extract on serum biochemical factors levels and body weight: Compare to normal saline group, serum glucose levels significantly increased in the diabetic rats $(\mathrm{p}<0.05)$. Serum glucose levels in diabetic rats receiving 250 and $500 \mathrm{mg}$ doses of herb extract 
KHOJASTEH S. M. B., et al.

(treatment groups) significantly decreased compare to diabetic group (Table 1).

The cholesterol level in the test groups was significantly lower than that of the diabetic group at the end of period experimental (Table 1). The present study demonstrates that orally administered extracts of Rosa canina fruits significantly reduced Cholesterol levels in the treatment groups (Table 1). It appears that, this plant has higher treatment effects on cholesterol levels then glucose. There was no significant difference in triglyseride levels in the treatment groups but in comparison with diabetic group differences were significant (Table 1).

Extract of Rosa canina significantly prevented loss of body weight caused by diabetes (Table 2).

Table 1. Glucose, triglyceride and cholesterol amounts in different groups

\begin{tabular}{llll}
\hline Groups & Glucose & Triglyceride & Cholesterol \\
\hline Control & $70.79 \pm 0.56^{\mathrm{a}}$ & $26.14 \pm 0.31^{\mathrm{a}}$ & $33.77 \pm 0.46^{\mathrm{a}}$ \\
Diabetic & $242.72 \pm 0.32^{\mathrm{c}}$ & $81.02 \pm 0.36^{\mathrm{c}}$ & $81.21 \pm 0.42^{\mathrm{d}}$ \\
D+250 & $205.26 \pm 0.42^{\mathrm{b}}$ & $75.88 \pm 0.43^{\mathrm{b}}$ & $47.45 \pm 0.29^{\mathrm{c}}$ \\
D+500 & $204.46 \pm 0.74^{\mathrm{b}}$ & $75.22 \pm 0.47^{\mathrm{b}}$ & $45.92 \pm 0.60^{\mathrm{b}}$ \\
\hline
\end{tabular}

The data are given as mean \pm standard error of the mean. $\mathrm{n}=$ Number of animals in each group (8 rats per group), values are statistically significant at $(\mathrm{p}<0.05)$. Variable letters in each column indicate significantly different between groups.

Table 2. Final body weight $(g)$ mean at the end of period experimental.

\begin{tabular}{lllll}
\hline Parameter & Control & Diabetic & D+250 & D+500 \\
\hline FinalBody & $227.37 \pm 5.71$ & $145.12 \pm 4.35$ & $239.37 \pm 12.5$ & $234.62 \pm 10.79$ \\
Weight $(\mathrm{g})$ & & & & \\
\hline
\end{tabular}

\section{DISCUSSION}

Diabetes is a major lifestyle disease nowadays. Proper management of the disease is very essential. The majority of the experiments confirmed the advantage of medicinal plants with hypoglycaemic effects in the management of diabetes mellitus. Medicinal plants are used for anti-diabetic purpose for decades. In this study, the ethanol extract of $R$. canina $\mathrm{L}$ fruits and its fractions were screened for hypoglycemic and antidiabetic activities. The effects of the aqueous and ethanol extracts of $R$. canina $\mathrm{L}$ fruits on blood glucose level of normoglycemic rabbits were investigated and did not show any hypoglycemic activity. In another study, a single oral administration of trans-tiliroside, isolated from seeds of $R$. canina, $\mathrm{L}$ has shown hypoglycemic activity at a dose of $10 \mathrm{mg} / \mathrm{kg}$ in normoglycemic mice. Daels-Rakotoarison et al., (2010) found that a rose hip acetone/ water extract was able to scavenge reactive oxygen species. As seen in the both studies just only normoglycemic animals have been used Moreover, it is well known that the rose hip is rich in polyphenols (e.g., flavonoids and phenolic acids) that display an antioxidant properties as. Some flavonoids have hypoglycemic properties because they improve altered glucose and oxidative metabolisms of diabetic states.

Quercetin is an important flavonoid known to possess an extensive array of pharmacological activities. Intraperitoneal administration of quercetin to normal as well as streptozocininduced diabetic rats resulted in marked reduction in plasma glucose level of diabetic animals while the glucose level of the normoglycemic rats remained unalterd. Quecrcetin also suppressed the glucose level in diabetic rats in glucose tolerance tests and reduced plasma cholesterol and triglycerides significantly. In addition extracts from the rose hip plasma triglyceride and free fatty acid levels were significantly reduced. Also in the other study quercetin existence in methanol extract Rosa canina $\mathrm{L}$ was proved. On the other hand significant correlation was observed between $\mathrm{H} 2 \mathrm{O} 2$ scavenging activity and the total phenol content of $R$. canina L. Our conclusions showed that phenolic compounds decreased levels of glucose, triglycerides and cholesterol.

Results of one study suggested that plasma cholesterol and triglyceride concentrations were significantly lower after the rose hip oil diet than in the control animals which is in accordance 
KHOJASTEH S. M. B., et al.

with our findings. In the present study, the cholesterol level of $\mathrm{RC}$ in the test groups was significantly lower than that of the diabetic group during all study days (Table 1).

The effects of aqueous and ethanol extracts on blood glucose were investigated in rabbits. After collecting a fasting blood sample, group 1 (control) was given orally $1 \mathrm{~mL} / \mathrm{kg}$ saline, groups 2 and 3 aqueous rose hip and seed extract $(2 \mathrm{~g} / \mathrm{kg}$ and $4 \mathrm{~g} / \mathrm{kg}$ of original dry starting material), groups 4 and 5 ethanol rose hip and seed extract $(200 \mathrm{mg} / \mathrm{kg}$ and $400 \mathrm{mg} / \mathrm{kg}$ ), group 6 (glucose control) $70 \%$ glucose $1 \mathrm{~g} / \mathrm{kg}$ and group 7 aqueous extract $2 \mathrm{~g} / \mathrm{kg}$ suspended in glucose solution. None of the extracts had a blood glucose lowering effect (. However, for the constituent trans-tiliroside a blood glucose lowering effect after glucose loading ( $1 \mathrm{~g} / \mathrm{kg}$ i.p.) was demonstrated in doses up to $10 \mathrm{mg} / \mathrm{kg} /$ day. In previous studies, the ethanol extract of Rosa canina $\mathrm{L}$ fruits in diabetic rats at $250 \mathrm{mg} / \mathrm{kg}$, p.o. for 7 days treatment, possessed a noteworthy hypoglycemic activity. Further, chloroform, ethyl acetate, butanol and aqueous extract of Rosa canina L were also tested in the diabetic rats and the results showed that aqueous extract possessed significant anti-diabetic activity compared to the other extract. Our findings are also in agreement with these reports. In this study, the ethanolic extract of Rosa canin L a cause in gaining weight in rats diabetic. The results of this study are in accordance with Orhan et al., (2009) which showed that R.canina $\mathrm{L}$ increased the body weight of diabetic rats.

The diabetic rats lose their weights significantly. In summary, although Rosa canina L extract could reduce blood glucose in diabetic groups, the considered doses showed significant differences between treatment groups with the control group in serum glucose and triglyceride levels. The Rosa canina can be used synergism with glucose-lowering drugs. Further studies are necessary to isolate and identify the active hypoglycemic compounds in $R$. canina fruits as well as elucidating their mechanisms of action.

\section{CONCLUSION}

The present study demonstrated that the Rosa canina L fruit extract display an antidiabetic effect in an in vivo animal model. The high level of antioxidant activity from our extract is probably co-responsible for the antidiabetic processes. These results support previous data from the literature and provide basis to further investigate the potential role of Rosa canina $\mathrm{L}$ as adjuvant therapeutic tool for the management of diabetes related diseases.

\section{Ethical issues}

All the procedures were carried out under the ethical guidelines of Tabriz University of sciences.

\section{Conflict of Interests}

None declared.

\section{REFRENCE}

1. Murugesh, K., Yeligar, V., Dash ,D.K., Sengupta, P., Maiti ,B.C. and Maity ,T.K., Antidiabetic, antioxidant and antihyperlipidemic status of Heliotropium zeylanicum extract on streptozotocininduced diabetes in rats. Biol Pharm Bul, 29: $2202-5,2006$.

2. Kumar, S., Kavimani, S., Jayaveera ,K.N., A Review on Medicinal plants with Potential Antidiabetic Activity. International Journal of Phytopharmacology, 2 (2), 53-60, 2011.

3. Shane-McWhorter, L., Botanical dietary supplements and the treatment of diabetes: What is the evidence? Curr. Diab. Rep, 5: $391-8,2005$.

4. Zareba, G., Serradell, R., Castaner, R., Davies, S.L., Prous ,J. and Mealy ,N,. Phytotherapies for diabetes. Drugs Future, 30: $1253-82,2005$.

5. Gagliardino, J. J., Physiological endocrine control energy homeostasis and postprandial blood glucose levels. Eur. Rev. Med. Pharmacol. Sci, 9:75-92, 2005.

6. Lernmark, A., Type I diabetes. Clin. Chem, 45: 1331-1338, 1999.

7. Dey, L., Attele ,A.S. and Yuan ,C.S,. Alternative therapies for type 2 diabetes. Altern. Med. Rev.7:45-58, 2002.

8. Gilbert, M. P. and Pratley, R. E., Efficacy and safety of incretin-based therapies in patients with type 2 diabetes mellitus. Eur. J. Intern. Med, 20:S309-S318, 2009.

9. Marles, R. and Farnsworth, N. R., Antidiabetic plants and their active constituents. Phytomedicine, 2: 137-146, 1995.

10. Nilson ,O., Rose In: Flora of Turkey and the East Aegean Islands. Davis P.H, Ed, Edinburgh: Edinburgh University Press, 4: 106-128, 1997. 
11. Davis, P. H., Flora of Turkey and the East Aegean Islands.Edinburgh University Press. Edinburgh, UK, 1972.

12. Yeşilada, E., Biodiversity in Turkish Folk Medicine. In Biodiversity: Biomolecular Aspects of Biodiversity and Innovative Utilization; Sener B., Ed. Kluwer Academic/Plenum Publishers: London UK. pp, 119-135, 2002.

13. Haas, L. F., Rosa canina (dog rose). Journal of Neurology, Neurosurgery and Psychiatry, 5: 470, 1995.

14. Chrubasik, C., Roufogalis ,B.D ., MüllerLadner, U., Chrubasik, S., A systematic review on the Rosa canina effect and efficacy profiles. Phytother. Res, 22: 725733, 2008.

15. Soon, Y. Y. and Tan, B. K. H., Evaluation of the hypoglycemic and antioxidant activities of Morinda offi cinalis in streptozotocin-induced diabetic rats. Singapore Med J, 43: 77 - 85, 2002.

16. Sadigh-Eteghad, S., Mirzaei, H., FarzamPour, S. and Kahnamui, S., Inhibitory Effects of Endemic Thymus vulgaris and Mentha piperita Essential Oils on Escherichia coli O157:H7. Research Journal of Biological Science, 4(3), 340-4. 2009.

17. Eidi, M., Eidi, A. and Zamanizadeh, H., Effect of Salvia officinalis L. Leaves on Serum Glucose and Insulin in Healthyand Streptozotocin-Induced Diabetic Rats. Journal of Ethnopharmacology, 100(3), 310-13, 2005.

18. Gharagozlou, M. J., Araghchian, M., Shahtaheri, S. M. and Radmehr, B., Laboratory Animals, Biology, Anatomy, Application and Pathology. Bizhan publication, p,111-27. ISBN:9649567011, 2006.

19. Atalay, M., Oksala, N. K., Laaksonen, D. E., Khanna, S., Nakao, C., Lappalainen, J., Roy, S., Hänninen, O., Sen, C. K., Exercise Training Modulates Heat Shock Protein Response in Diabetic Rats. J Appl Physiol, 97: 605-611, 2004.

20. Sezik, E., Aslan, M., Yélilada, E. and Ito, S., Hypoglycaemic activity of Gentiana olivieri and isolation of the active constituent through bioassay-directed fractionation techniques. Life Sci,76: 1223 $-38,2005$.

21. Bnouham, M., Ziyyat, A., Mekhfi, H., Tahri, A., Legssyer, A., Medicinal plants with potential antidiabetic activity - A review of ten years of herbal medicine
KHOJASTEH S. M. B., et al. research (1990-2000). Int J Diabetes \& Metabolism, 14:1-25, 2006.

22. Deliorman Orhan, D., Aslan, M., Endo $\pi$ du, N., Ergun, F. and Yeẃilada, E., Evaluation of the hypoglycemic effect and antioxidant activity of three Viscum album subspecies (European mistletoe) in streptozocindiabetic rats. J Ethnopharmacol, 98 : 95 $102,2005$.

23. Daels-Rakotoarison, D. A., Gressier, B., Trotin, F., Brunet, C., Luyckx, M., Dine, T., Bailleul, F., Cazin, M., Cazin, J. C., Effects of Rosa canina fruit extract on neutrophil respiratory burst. Phytotherapy Research,16:157-161, 2002.

24. Bravo, L., Polyphenols: chemistry, dietary sources, metabolism, and nutritional significance. Nutrition Reviews, 56: 317333, 1998.

25. Hvattum, E., Determination of phenolic compounds in rose hip (Rosa canina) using liquid chromatography coupled to electrospray ionisation tandem mass spectrometry and diode-array detection. Rapid Communication in Mass Spectrometry, 16:655-662, 2002.

26. Fecka, I., Qualitative and quantitative determination of hydrolysable tannins and other polyphenols in herbal products from meadowsweet and dog Rose. Phytochemical Analysis, 20:177-190, 2009.

27. Guo W, Kong E, Meydani M (2009). Dietary polyphenols, inflammation, and cancer. Nutrition and Cancer 61:807-810.

28. Vessal, M., Hemmati, M., Vasei, M., Hypoglycemic effects of quercetin in streptozocin-induced diabetic rats. Comparative Biochemistry and Physiology C: Toxicology and Pharmacology, 135C: 357-364, 2003.

29. Ninomiya, K., Matsuda, H., Kubo, M., Morikawa, T., Nishida, N., Yoshikawa, M., Potent anti-obese principle from Rosa canina: structural requirements and mode of action of transtiliroside. Bioorg Med Chem Lett,17: 3059-3064, 2007.

30. Jamei, R., Fattahi, S., HosseiniSarghein, S., Antioxidant and antiradical activities of Rosa caninaand Rosa pimpinellifoliafruits from West Azerbaijan. Iranian Journal of Plant Physiology,Vol (2), No (4), 523-529, 2012.

31. Kilicgun Hand Altiner ,D., Correlation between effect mechanisms and polyphenol content of Rosa canina. Pharmacog Mag, 6(23): 238- 241, 2010. 
32. Gonzales, I., Celedon, G., Montalar, Y., Lutz, M., Dietary rose hip and corn oils effects on biliary and plasma lipid patterns,and hepatocyte membranes fluidity in rats. Nutr Rep Int, 40: 271-280, 1989.

33. Can, A., Akev, N., Sütlüpinar, N., Effect of rose hips on blood glucose level. Acta Pharm Turc, 34: 17-22, 1992.

34. Orhan, N., Aslan, M., Hosbas, S., Deliorman, O. D., Anti-diabetic effect and
KHOJASTEH S. M. B., et al.

antioxidant potential of Rosa caninafruits.Pharmacogn Mag, 5(20): 30915, 2009.

35. McAnuff, M.A., Omoruyi, F.O., Morrison, E.Y., St, Asemota, H.N., Changes in Some Liver Enzymes in Streptozotocin-induced Diabetic Rats fed Sapogenin Extract from Bitter Yam (Dioscorea polygonoides) or Commercial Diosgenin. West Indian Med J, 54 (2): 97-101, 2005. 